NBER WORKING PAPER SERIES

\title{
GROUP CORRUPTION VIA SEQUENTIAL BARGAINING IN A HIERARCHICAL ORGANIZATION
}

\author{
Fan-chin Kung \\ Ping Wang \\ Quan Wen \\ Working Paper 29759 \\ http://www.nber.org/papers/w29759 \\ NATIONAL BUREAU OF ECONOMIC RESEARCH \\ 1050 Massachusetts Avenue \\ Cambridge, MA 02138 \\ February 2022
}

We are grateful for valuable comments and suggestions by David Austin-Smith, Marcus Berliant, Gary Biglaiser, Rick Bond, Michael Chwe, Tom Gresik, Joe Harrington, Derek Laing, Jennifer Reinganum, Alison Watts, Asher Wolinsky and seminar participants at Penn State, Purdue, Hong Kong University of Science and Technology, Vanderbilt, University of Washington, as well as the Midwest Economic Theory Conference, the Society for Advanced Economic Theory Conference, the Southeast Economic Theory Conference, and the Taipei International Conference on Industrial Organization. Needless to say, the usual disclaimer applies. The views expressed herein are those of the authors and do not necessarily reflect the views of the National Bureau of Economic Research.

NBER working papers are circulated for discussion and comment purposes. They have not been peer-reviewed or been subject to the review by the NBER Board of Directors that accompanies official NBER publications.

(C) 2022 by Fan-chin Kung, Ping Wang, and Quan Wen. All rights reserved. Short sections of text, not to exceed two paragraphs, may be quoted without explicit permission provided that full credit, including $\odot$ notice, is given to the source. 
Group Corruption via Sequential Bargaining in a Hierarchical Organization

Fan-chin Kung, Ping Wang, and Quan Wen

NBER Working Paper No. 29759

February 2022

JEL No. C78,D23,D73,L22

\begin{abstract}
$\underline{\text { ABSTRACT }}$
We develop a framework of group corruption via back-door negotiations between an outside initiator and an authority of decision-makers in a hierarchical organization. We examine the role played by the architecture of a multi-tier authority and determine under such a structure how bargaining proceeds, in what order, and when it breaks down. We verify that equilibrium bargaining sequence proceeds as a chain through decision-making agents, regardless of the hierarchy of the organization. We prove the existence of a compromised equilibrium, where the decision of the authority is compromised, and establish sufficient conditions under which the most natural bottom-up bargaining configuration arises in equilibrium where a proposer negotiates with an immediately higher ranked respondent, starting with the initiator bargaining with the lowest ranked decision-maker in the organization. We then show the circumstances under which a top-down or a non-monotonic equilibrium configuration may emerge, and those under which the deal may break down. This enables us to capture a rich array of group corruptive configurations as observed. We conclude by investigating the extension to multi-tier authorities with multiple agents of the same rank in each tier, such as in a tree hierarchy.
\end{abstract}

Fan-chin Kung

Department of Economics

East Carolina University

Greenville, NC 27858

kungf@ecu.edu

Ping Wang

Department of Economics

Washington University in St. Louis

Campus Box 1208

One Brookings Drive

St. Louis, MO 63130-4899

and NBER

pingwang@wustl.edu
Quan Wen

Department of Economics

University of Washington

Seattle, WA 98195

wenq2@uw.edu 
"He should not effect the corruption of the uncorrupted as of water by poison, for, it may well happen that a cure may not be found for one corrupted. ... $[\mathrm{A}]$ nd the mind, perverted by the fourfold secret tests may not turn back without going to the end, remaining fixed in the will of spirited persons." (The Kautil̄̄ya Arthaśāstra: An English Translation with Critical and Explanatory Notes, University of Bombay, 1960)

\section{Introduction}

The so-called "back-door" negotiations, between an outside "initiator" and a group of decision-makers in a political or business organization, have been observed not only in pocket boroughs prior to the 1832 Act of the U.K. Parliament but almost everywhere (cf. Aidt, 2003). ${ }^{1}$ As documented by Rose-Ackerman (1996), many such "dirty deals" occurred (i) via informal links in the absence of a formal auction and (ii) with involvement of relevant decision makers in a decentralized fashion (i.e., with sequential negotiations). While these special features of informal and decentralized negotiations are crucial for understanding the process of back-door negotiations and the outcome of group corruption, little has been done towards building a formal framework to analyze the process and outcomes of such negotiations. Our paper intends to fill this gap, by developing a multi-stage sequential bargaining framework particularly suited for examining the nexus between organizational hierarchy and group corruptive behavior, aiming to determine under such a structure how bargaining proceeds, in what order, and when it breaks down.

For illustrative purposes, we restrict our attention to group corruptive behavior that may encounter violations of laws and orders, social norms, or ethics. The term "bribes" used herein may be unlawful or illegal, or legal but anti-social norm or unethical in forms of meals and business gifts for carrying out back-door negotiations. ${ }^{2}$ In their celebrated study, Blanchard and Kremer (1997) illustrate how market imperfection can cause a breakdown of sequential bargains between firms along the production chain when the chain is long and the foregone cost incurred by each firm, especially the upstream firm farthermost from the final producer, is high. Motivated by their paper on disorganization, we stress that an appropriate

\footnotetext{
${ }^{1}$ For example, using a matched employer-employee longitudinal dataset from Italian local politicians, Cingano and Pinotti (2013) find the prevalence of allocating public goods to favor private businesses, under which favored firms gain a revenue premium of $5.7 \%$ on average.

${ }^{2}$ In Mauro (1995), an index of corruption, constructed by the Economist Intelligence Unit, is used in which corruption is measured by "the degree to which business transactions involve corruption and questionable payments."
} 
model of sequential bargains is suited for characterizing group corruptive behavior when an initiator approaches decision-makers in an organizational hierarchy. Bargaining theory has been used to address bribery and corruption (cf. Rose-Ackerman, 1978; Muthoo, 1999). Our emphasis is, however, on the role played by the architecture of a multi-tier authority and the endogenously determined sequence of bargains. ${ }^{3}$

A leading example is documented by Olken and Barron (2009): Along the trucking route to Nanggroe Aceh Darussalam Province in Indonesia via North Sumatra Province, illegal payments were frequently observed at checkpoints (controlled by police/military) and weigh stations (controlled by local governments), where monitoring was turned into a rentextraction device with almost all truck drivers paying bribes to avoid penalty imposed on weight exceeding the maximum limit. This group of authority thus forms a monitoring chain (cf. Strulovici, 2021) and the success of the bargaining process would depend crucially on the coordination of the entire group in a fashion similar to the process of competitive bribery in legislation (cf. Rose-Ackerman, 1978). While the bribery process in Aceh trucking route is largely fixed by the geographical ordering and the ruling authorities cannot be clearly ranked, in more general environments authorities should be allowed to have different ranks - and hence heterogeneous ruling power and foregone costs, while the bargaining sequence should be allowed to be determined in equilibrium rather than given ex ante by nature. Under such general environments, we inquire how bargaining would proceed and whether the process of sequential negotiations would end in success or not.

To address these questions, our framework departs from conventional multilateral bargaining models: A final agreement is reached by a sequence of bilateral agreements along the bargaining process in which the bargaining configuration that describes the entire bargaining sequence is endogenously determined. The form of a sequence of bilateral negotiations is a consequence of secrecy as observed in practice (stressed by Shleifer and Vishny, 1993, and Rose-Ackerman, 1996). To enable the determination of the potentially complicated bargaining configuration, we regard the hierarchical structure of the authority as exogenously given. ${ }^{4}$

\footnotetext{
${ }^{3}$ For a comprehensive discussion of hierarchies, the reader is referred to the now-classic books of Williamson (1975) and Tullock (1992).

${ }^{4}$ The assumption of an exogenous hierarchical structure follows in the spirit of the hierarchical contracting literature, such as the study by Melumad, Mookherjee and Reichelstein (1995). It contrasts with the endogenous firm structure model developed by Bolton and Dewatripont (1994) and the organizational design literature where, for example, Laffont and Tirole (1990) and Kofman and Lawarrée (1993) consider a threelevel hierarchy of a principal-supervisor-agent problem to examine how effective individual performance can be monitored (see also a comprehensive survey by Tirole 1992).
} 
Importantly, what is relevant here is the hierarchy of the decision-making authority, not that of the organization itself. The bargaining process proceeds with a sequence of bilateral bargains, where at each stage of the bargain the stay-exit decision of a proposer is endogenous as well. To capture the essence of coordination and simplify the analysis, we adopt cooperative Nash (1950) bargaining solution, given hierarchy-dependent transaction costs and disagreement losses. Under this setting, the subgame perfect equilibrium sequence of bargaining configuration must be cost minimizing.

More specifically, at each bilateral bargaining stage, a proposer is endogenously determined and responsible for carrying the agreement over to the next bargaining stage. Two methodological remarks are in order. First, the bilateral bargaining setting intended to capture the secretive nature of corruption contrasts with multilateral bargaining games of proposing to a wining coalition (cf. Eraslan and McLennan 2013). Second, the endogenous determination of the proposer at each stage is critical for influencing equilibrium bargaining configurations on which we focus; as such, our setting departs from the conventional wisdom of (i) alternating offers with proposers and respondents taking turns (cf. Rubinstein, 1982; Friedenberg, 2019), and (ii) random-draws of proposers with everyone having an equal chance to become the proposer at each stage (cf. Baron and Ferejohn, 1989; Tsai and Yang, 2010; Eraslan and McLennan, 2013). The initiator, by construction, is the proposer at the start of the game, who proposes to share a potential gain or value. At each stage, two key elements determining the equilibrium configuration are whom the proposer will bargain with (the respondent) and who the next proposer will be. An equilibrium configuration is a sequence of bargains along which no proposer is better-off by altering his decision regarding with whom to bargain and who the next proposer is. A nondegenerate compromised equilibrium obtains when all agents have reached agreements sequentially to realize the potential value, under a participation condition of positive payoffs. The participation condition requires the initial value to be shared among participants to be large enough, under which the mind, despite facing the possibility of being detected, may not turn back without going to the end (as in the opening quote above). Otherwise, bargaining may break down, that captures the case studied by Blanchard and Kremer (1997). We show that the equilibrium configuration can be "monotone," featuring a realistic "bottom-up" sequence, in the benchmark setting, where a proposer negotiates with immediately higher ranked agents. We further show that the other monotone, "top-down," sequence and non-monotonic (mixed) configurations may also arise when bargaining costs become more concave. Thus, we are able to obtain the 
case of bargaining breakdown as well as a rich array of group corruptive configurations as observed. Finally, we conclude the paper by providing conjectures about the consequence of allowing a more general transactions cost schedule to depend not only on the difference in ranks but on the active player's position in the hierarchy.

Our study facilitates better understanding of players' behavior in informal and decentralized negotiations that are of particular relevance to bribery, political lobbying, and government corruption. Besides the related literature cited above, there are other studies focusing on the causes of corruption. For example, Shleifer and Vishny (1993) point out that monopoly power and institutional secrecy are the main determinants of the level of corruption. While Mookherjee and Png (1995) highlight the important role of compensation policy in reducing bribery of a pollution inspector, Tirole (1996) emphasizes how collective reputations may induce persistent corruption. Bac (1996) and Bag (1997) illustrate the relationship between the structure of monitoring hierarchies and the number of bribed members in an organization. Banerjee (1997) argues that corruption may be a consequence of the conflicting objectives between the government (the principal) and bureaucrats (agents). Those interested in this more remotely related literature are referred to the comprehensive survey articles by Bardhan (1997) and Aidt (2003). ${ }^{5}$

\section{Bargaining with an Authority}

Let $\boldsymbol{S}$ denote the set of agents in a hierarchical organization of interest. An initiator I outside of the organization is attempting to influence the hierarchy's decision by informal backdoor negotiations with agents concerning a potential profitable deal. Given this particular deal, a certain subset of relevant agents in $\boldsymbol{S}$ are involved in making decisions. ${ }^{6}$ The set of these decision-making agents is called the authority, denoted by $\boldsymbol{A} \subseteq \boldsymbol{S} .^{7}$ Depending on institutional regulations and socioeconomic factors, the decision-making authority may feature a particular hierarchical structure. Although the organization can have a general

\footnotetext{
${ }^{5}$ Of particular interest, Aidt (2003) argues three necessary conditions for corruption to arise and persist are (i) discretionary power of the authority, (ii) extraction of economic rents and (iii) weak institutions for detection and punishment.

${ }^{6}$ As emphasized by Rosen (1982), the authority plays an important role in control, decision-making and distribution of earnings in the associated organization. See Aghion and Tirole (1997) for detailed definitions of the formal authority (the right to decide) and the real authority (the control of decisions). Throughout this paper, we consider these relevant agents as both formal and real authority. See also Sah and Stiglitz (1986) for hierarchies in the economy.

${ }^{7}$ For example, the initiator could be a salesman, a contractor, or a special-interest contributor, whereas the authority could be a group of decision-making agents in a corporation, a government office, or a political party.
} 
and complex structure, due to the secrecy of the deal that is unlawful, anti-social norms or unethical, the negotiations are conducted one-on-one, in a sequence of bilateral bargains within the authority $\boldsymbol{A}$. Thus, bargaining sequence proceeds as a chain through authority agents, regardless of the hierarchy of the organization $\boldsymbol{S}$. Attention is focused on bargaining with a strict ordering of ranks. Each agent has a distinct rank, so that each bilateral bargaining pairs are of different ranks. Our sequential bargaining framework captures the multi-tier authority of Aceh trucking studied in Olken and Barron (2009), the "monitoring chain" investigated by Strulovici (2021), the "tunneling" in Moscow government procurement allocation to a private firm (Inteko) examined in Mironov and Zhuravskaya (2016), the local government allocation of China's central government investment projects to favored local businesses explored by Bai, Hsieh, and Song (2016), the government investigation of citizens' compliance with regulations analyzed by Angelucci and Russo (2022) when multiple officials are involved, as well as many bargaining structures used in models of corruption where the sequence of bargain features a finite number of rounds. ${ }^{8}$ Without loss of generality, it is assumed that the ultimate final game play (or the principal in most corruptive games) is benevolent and passive, taking the recommendation by the authority. ${ }^{9}$ In this regard, our model may be viewed as a model of "corruption with a benevolent principal" (cf. Aidt, 2003).

Going beyond the leading example of Aceh trucking, we now describe a more general environment to motivate how the organizational hierarchy and the order of sequential bargains may play a role. Consider a case in which a piece-wage salesperson (the initiator), Ben, is trying to promote a new quantum computing device called OfficeMaster, to the state government of Corrupto in which formal, transparent auction is not taken place. The decision-making authority in the state government of Corrupto consists of a young but fearless officer, Dougal, in the purchase department, the division head of the Purchase Department, Tom, and the state governor, Jerry. That is, the approval of the purchase order requires signatures by all in the authority - Dougal, Tom, and Jerry. This decision process can be influenced by Ben's informal negotiations with Dougal/Tom/Jerry. Given the cost of the OfficeMaster, Ben has room to adjust his commission on sales (the potential value of the

\footnotetext{
${ }^{8}$ Our model cannot nest, though, the circular network of peer monitoring considered by Levine and Modica (2016) under which there is possibly an unlimited number of audit rounds.

${ }^{9}$ The principle can be the voters in political organizations or the shareholders in business corporates. To achieve the purposes of our study, the typical principle-agent problem under incomplete information is abstracted from the present paper. As such, we also avoid the complexity associated with "who will guard the guardians" (cf. Hurwicz, 2007).
} 
deal) by providing side-payments (bribes) to the authority of the Corrupto State government upon the success in selling OfficeMaster. An immediate problem arises: To whom should Ben approach to begin the process? By approaching Dougal first, the time and pecuniary bargaining/communication costs and the costs of bribes (all summarized into the transactions costs) are low, but a successful negotiation need not guarantee much as the fearless but powerless Dougal must seek approval from his two bosses. In particular, his bosses may suffer disagreement losses in forms of pecuniary penalties (salary cut) or nonpecuniary penalties (delay in promotion, demotion or even layoff, in conjunction with damages in reputation), should the negotiation process get exposed. As an alternative, Ben may, by incurring higher transactions costs (more wining, dining, and bribing), negotiate with the highest ranked Jerry to reach a partial agreement and let Jerry work out the deals with Tom and then Dougal, by exercising his power of authority. The benefit of this starting-from-the-top route is to lower subsequent transaction costs facing the lower ranked agents. Disagreement losses are likely to be higher for Tom than for Dougal because Dougal has less to lose given his lightweight position while such a disagreement loss for Tom proposing to Jerry is likely much greater as he puts his division-head reputation at stake. Due to the power structure in the hierarchy, a higher ranked agent incurs relatively low or even zero transactions costs in negotiating with a lower ranked agent. Additionally, Ben may also approach the middle-ranked Tom first. Moreover, in any of these cases, who should carry out the rest of bargains after the starting round must also be determined. Which bargaining configuration arises in equilibrium has not been formalized, thus motivating the present paper that develops a multi-stage bargaining framework to examine the bargaining process of group corruption.

The decision authority is hierarchical where every agent has a rank. Consider a linear hierarchy featuring a single agent who is superior to all the other agents. All agents have at most one immediate subordinate and at most one immediate supervisor. This type of hierarchical structure is referred to as a sequential chain. In a sequential chain, the ordering is strict and complete. There are $N$ decision-making agents, labeled by ranks: $\mathbf{A}=\{1,3, \ldots, N\}$. There is a strict ordering of agents and, for any $i, j \in \mathbf{A}, i$ is superior to $j$ if $i>j .{ }^{10}$. The initiator is set to have rank $R(I)=0$, as an outsider to the hierarchy. The potential value of an agreement between the initiator and the authority is $V_{0}$, and it will be realized when there is a final agreement. Bargaining is conducted via $N$ stages of bilateral bargains. An agreement is reached if each bilateral agreement in all $N$ stages is agreed upon. Our game resembles

\footnotetext{
${ }^{10}$ For a detailed discussion of this mathematical relation in the theory of hierarchies, the reader is referred to a comprehensive survey by Radner (1992).
} 
that considered in the competitive bribery model by Rose-Ackerman (1978) in which the content of the proposed legislation to bargain is fixed and the proposal would fail to pass in the absence of corruption.

A bargaining stage $t$ proceeds with a proposer $p_{t}$ carrying a continuation value $V_{t}$, which is what she receives at the previous bargaining stage, to propose a respondent $a_{t+1} \in \mathbf{A}$, chosen from players who have not moved yet. The two players $p_{t}$ and $a_{t+1}$ negotiate how to share the proposer's continuation value $V_{t}$. The respondent can reject the proposal, then the game ends and no value will be realized. If respondent accepts the bargain, the proposer will decide whether to exit the game or to continue proposing at the next stage. This, in turn, decides who, between $p_{t}$ and $a_{t+1}$, will be the proposer $p_{t+1}$ at the next stage; that is, $p_{t+1} \in\left\{p_{t}, a_{t+1}\right\}$. At the first stage, the initiator is the proposer carrying the potential value of agreement, $V_{0}$. This negotiation process continues with the new proposer's payoffs as the continuation value to be divided with a newly selected respondent. This bargaining sequence continues until every agent in the authority has accepted a bargain, or someone rejects and terminates the sequence. When a bilateral bargaining fails to reach an agreement at any stage, the whole deal is off and disagreeing agents at that stage incurs disagreement losses. Denote the stage $t$ bilateral bargaining as $\left(p_{t}, a_{t+1}\right)$, with the former agent being the proposer and the later the respondent.

At each stage, the proposer may incur a transactions cost when approaching the respondent, and a potential disagreement loss in case of disagreement. ${ }^{11}$ For the sake of simplicity, it is assumed that the respondent would not need to pay a transaction cost and there is no potential disagreement loss. Proposers may have different transaction costs and potential disagreement losses depending on their ranks in the hierarchy, which is specified below. Transactions costs in the hierarchy are incurred only if the proposer ranks below the respondent. Denote rank difference between the respondent and the proposer at stage $t$ as $r_{t} \equiv R\left(a_{t+1}\right)-R\left(p_{t}\right)$. Formally,

Assumption 1. (Transaction Cost) Transaction cost function takes the following form: $C\left(p_{t}, a_{t+1}\right)=c\left(r_{t}\right)$ if $r_{t}>0$, and 0 otherwise, where $c\left(r_{t}\right)$ is increasing and weakly convex in rank difference $r_{t}$.

As a consequence of the power of hierarchy, a higher rank agent incurs no transaction cost to negotiate with a lower rank agent. Moreover, when a lower rank agent approaches a higher

\footnotetext{
${ }^{11}$ While the disagreement loss is standard, our transaction cost captures that emphasized by Levine and Modica (2016) in an extension of "renegotiation-feasible" equilibrium where collusion can take place only if a meeting with costly participation is held.
} 
rank agent, the transaction cost incurred depends on the rank difference. ${ }^{12}$ The transaction cost is increasing in rank difference. This comes from that the difficulty of approaching a higher rank is increasingly larger and that the information an agent has on others in the organization decreases with distance in rank. Agents may know better other agents closer in rank. For example, if one has regular contact with immediate subordinates and supervisors, but much less contact with agents more than two ranks away. This lack of inside information means that the bargaining cost increases faster than rank difference, hence is weakly convex. For convenience, the transaction cost is assumed to depend only on rank difference rather than the ranks of both bargaining parties. A general form of the transactions cost schedule will leave the main results qualitatively unchanged but complicate the analysis significantly. ${ }^{13}$ In Section 4 below, we shall relax the natural but somewhat strong convexity assumption to obtain richer equilibrium outcomes.

The disagreement loss measures what a proposer may lose if the under-the-table bargain is detected. Such a loss depends on the proposer's position, associated with the potential costs from job demotion, layoff, reputation damage, or other forms of penalty from the prosecution of bribing.

Assumption 2. (Disagreement Loss) Disagreement loss function takes the following form: $L\left(p_{t}\right)=\pi \cdot l\left(R\left(p_{t}\right)\right)$, where $l(0)=0$ and $l(s)$ is increasing in $s$.

The loss is greater if the unsuccessful proposer has a higher rank. The initiator suffers the lowest potential disagreement loss as demotion and layoff are not applicable to her. While the loss is larger if the proposer has a higher rank, the probability of being detected $\pi \in(0,1)$ is assumed to be identical regardless of rank. As noted by Shleifer and Vishny (1993), "when the society is homogeneous and closely knit, as in East Asia, deviations from normal bribes are likely to become known to friends and family, and such knowledge is likely to spread." This cultural factor can be readily captured by our notion of detection probability, $\pi$.

\footnotetext{
${ }^{12}$ For example, a supervisor does not have to buy a dinner to bribe his subordinates. The reader may imagine that the transactions cost a higher-ranking agent incurred in bargaining with a lower ranked is a small value normalized to zero.

${ }^{13}$ In the concluding section, we give conjectures about the consequence of allowing a more general transactions cost schedule to depend not only on the difference in ranks but on the active player's position in the hierarchy.
} 


\section{Sequential Bargaining Equilibrium}

Bargaining respondents $a_{1}$ to $a_{N}$ are labeled according to the order they enter the game (the initiator will be labeled $a_{0}=I=p_{0}$ ). Bargaining starts at the initiation stage $t=0$. The initiator $a_{0}$ carries the initial value $V_{0}$ to bargain with a respondent - notably, under this normalization, all transactions costs and disagreement losses should thereby be viewed as the relative cost to the initial value of the deal. At every stage $t$, for $0 \leq t \leq N-1$, proposer $p_{t}$ carries a continuation value $V_{t}$ from the previous stage $t-1$. She chooses a rank $R\left(a_{t+1}\right)$ agent remaining in the game to be respondent $a_{t+1}$ at stage $t .{ }^{14}$ Apparently, the respondent may choose not to accept the bargain if the payoff is too low. To simplify the analysis, a participation condition is imposed, under which everyone receives a nonnegative payoff. Thus, we can focus attention on the bargaining configuration: A proposing order $R$ is an assignment function that maps a distinct rank $R\left(a_{t}\right) \in \mathbf{A}$ to respondent $a_{t}$. It determines the whole sequence of bargaining participants. Let $\Pi$ denote the set of all proposing orders. A proposer's exit choice after bargaining is denoted by $e\left(p_{t}\right) \in\{$ Exit, Stay $\}$. If $e\left(p_{t}\right)=$ Exit then $p_{t+1}=a_{t+1}$, and if $e\left(p_{t}\right)=S t a y$ then $p_{t+1}=p_{t}$. Thus, a strategy profile of the $N$-stage bargaining game is a bargaining configuration, $(R, e)$, composed of a proposing order $R$ and an exit choice $e$.

Proposer $p_{t}$ spends an out-of-pocket transaction cost $C\left(p_{t}, a_{t+1}\right)$ in the negotiation process. This leaves value $V_{t}-C\left(p_{t}, a_{t+1}\right)$ to be divided. If bargaining is not successful, the proposer suffers a loss $L\left(p_{t}\right)$ and the respondent gets zero. At each bilateral bargaining stage, players' payoff is determined by the Nash bargaining solution based on their corresponding transactions costs and potential disagreement losses. The proposer gets $w_{t}^{p}$ and the respondent gets $w_{t}^{r}$, where $w_{t}^{p}+w_{t}^{r}=V_{t}-C\left(p_{t}, a_{t+1}\right)$.

The exit payoff of the player who exits can be specified: (i) If proposer $p_{t}$ chooses to exit, she will receive stage $t$ proposer exit payoff $u_{t}^{p}=w_{t}^{p}$. Respondent $a_{t+1}$ carries continuation value $V_{t+1}=w_{t}^{r}$ into the next stage, $p_{t+1}=a_{t+1}$. (ii) If proposer $p_{t}$ stays and carries continuation value $V_{t+1}=w_{t}^{p}$ to the next stage, then $p_{t+1}=a_{t}$, and respondent $a_{t+1}$ exits the game and will receive stage $t$ respondent exit payoff $u_{t}^{r}=w_{t}^{r}$.

A compromised equilibrium is a bargaining configuration $(R, e)$ that is supported in subgame perfect equilibrium. No proposer is better-off by altering her decision concerning with whom to bargain and who should be the next proposer. Hence, the authority's decision is

\footnotetext{
${ }^{14}$ Agent identity is labeled as $a_{t}$ according to the stages they enter the game and $p_{t}$ is rather a role label denoting proposers.
} 
influenced and compromised by the initiator. A participation condition will guarantee that bargaining solutions are nonnegative, so everyone accepts the bargain. The corresponding equilibrium exit payoffs are denoted by $\left\{u_{t}^{m}\right\}_{t=0}^{N}, m \in\{p, r\}$. Notice that subscript $t$ is a stage label when an agent exits, not a personal label that matches $a_{t}$. For example, $u_{t}^{p}$ means the payoff when an agent exits the bargain at stage $t$ as a proposer. If all proposers choose to exit, then all agents have payoff $\left\{u_{t}^{p}\right\}_{t=0}^{N}$. But if $a_{t}$ chooses to propose in three stages, then $a_{t+1}$ exits at stage $t$ as a respondent with payoff $u_{t}^{r}, a_{t+2}$ exits at stage $t+1$ as a respondent with payoff $u_{t+1}^{r}$, and $a_{t}$ exits at stage $t+2$ as a proposer with payoff $u_{t+2}^{p}$. This proposer payoff is a function of the continuation value, $u_{t}^{p}\left(V_{t}\right)$. Notice that the last stage respondent $a_{N}$ will exit as a respondent with payoff $u_{N}^{r}$.

Consider the class of strategies where every leader exits after proposing once. $\bar{e}\left(p_{t}\right)=$ Exit for all $t$. Thus, agents at stage $t$ bargaining can be written as $\left(a_{t}, a_{t+1}\right)$, since $p_{t}=a_{t}$. This "always-exit" strategies $\bar{e}$ will be proven to be the equilibrium strategy in Proposition 2. It is convenient to define the sum of the disagreement loss and twice the transaction cost as the bargaining cost incurred by the proposer at stage $t$ :

$$
B C\left(a_{t}, a_{t+1}\right)=L\left(a_{t}\right)+2 C\left(a_{t}, a_{t+1}\right)
$$

Under the always-exit strategy, each bargaining stage proceed as follows: Proposer $a_{t}$ brings continuation value $V_{t}$ and proposes to respondent $a_{t+1}$. After spending bargaining cost $C\left(a_{t}, a_{t+1}\right)$, they bargain to divide $V_{t}-C\left(a_{t}, a_{t+1}\right)$. The proposer has disagreement payoff $-L\left(a_{t}\right)-C\left(a_{t}, a_{t+1}\right)$. The respondent can turn down the bargain and get disagreement payoff 0 . After stage $t$ bargaining, respondent $a_{t+1}$ will carry the continuation value $V_{t+1}=w_{t+1}^{r}$ into stage $t+1$, and proposes to $a_{t+2}$. If stage $t+1$ bargaining is successful, $a_{t+1}$ will receive proposer exit payoff $u_{t+1}^{p}\left(V_{t+1}\right)$. The stage $t$ bargaining feasibility set, and the corresponding Nash bargaining solution are depicted in Lemma 1 and Figure 1. (It will be assumed first that all $u_{t}^{p}\left(V_{t}\right)$ are linear in $V_{t}$, and later verified in Proposition 1).

Lemma 1. Suppose all $u_{t}^{p}\left(V_{t}\right)$ are linear in $V_{t}$ and bargaining features always-exit strategies $\bar{e}$. To a bargaining pair $\left(a_{t}, a_{t+1}\right)$ involved at stage $t=0, \ldots, N-1$, the bargaining feasibility set is a right triangle in the $u_{t}^{p}-u_{t+1}^{p}$ utility space composed of three points: $\left(V_{t}-C\left(a_{t}, a_{t+1}\right)-\left(u_{t+1}^{p}\right)^{-1}(0), 0\right),\left(-L\left(a_{t}\right)-C\left(a_{t}, a_{t+1}\right), u_{t+1}^{p}\left(V_{t}+L\left(a_{t}\right)\right)\right)$ and the disagreement point $\left(-L\left(a_{t}\right)-C\left(a_{t}, a_{t+1}\right), 0\right)$. The Nash bargaining solution is the circumcenter of the bargaining feasibility set (the midpoint of the hypotenuse),

$$
\left(w_{t}^{p}, u_{t+1}^{p}\left(w_{t}^{r}\right)\right)=\left(\frac{1}{2}\left(V_{t}-B C\left(a_{t}, a_{t+1}\right)-\left(u_{t+1}^{p}\right)^{-1}(0)\right), \frac{1}{2} u_{t+1}^{p}\left(V_{t}+L\left(a_{t}\right)\right)\right) .
$$




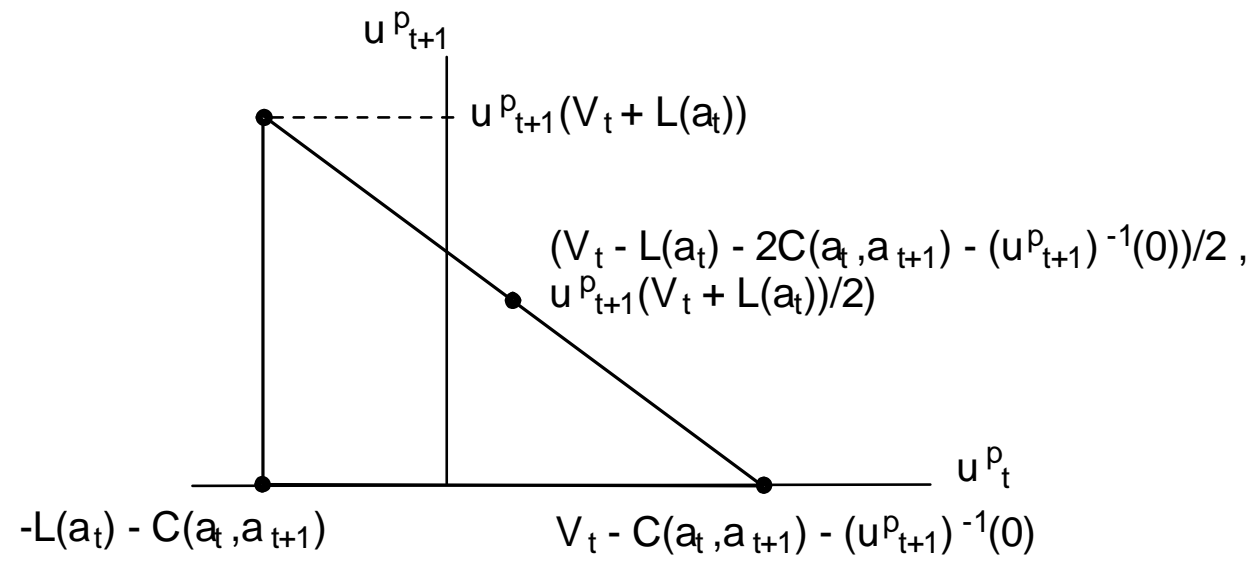

Figure 1: Nash bargaining solution

Proof. Notably, Nash bargaining is to find a solution in the $u_{t}^{p}-u_{t+1}^{p}$ utility space, but it is the net value $V_{t}-C\left(a_{t}, a_{t+1}\right)$ to be divided in the bargaining game. Under the condition that all $u_{t}^{p}\left(V_{t}\right)$ are linear in $V_{t}$, the translation from worth into utility space maintains a linear frontier of the bargaining feasibility set. Next, we check the end points of the stage $t$ bargaining frontier: A final payoff 0 for $a_{t+1}$ is the same as carrying on a continuation value $V_{t+1}=$ $\left(u_{t+1}^{p}\right)^{-1}(0)$. So, 0 payoff for respondent $a_{t+1}$ translates into a share of value $\left(u_{t+1}^{p}\right)^{-1}(0)$. At this end point, proposer $a_{t}$ is associated with payoff $V_{t}-C\left(a_{t}, a_{t+1}\right)-\left(u_{t+1}^{p}\right)^{-1}(0)$. At the other end point, the proposer gets her disagreement payoff $-L\left(a_{t}\right)-C\left(a_{t}, a_{t+1}\right)$, and respondent $a_{t+1}$ is associated with worth $V_{t}+L\left(a_{t}\right)$, which means payoff $u_{t+1}^{p}\left(V_{t}+L\left(a_{t}\right)\right)$. The Nash bargaining solution then follows immediately.

Consider a series of bargaining at stages $t=0, \ldots, N-1$ with the last respondent exiting with payoff $u_{N}^{r}=V_{N}$ and with no further action as the game is completed. We next demonstrate how the proposer's exit payoff $u_{t}^{p}$ and continuation value $V_{t+1}$ are determined at a stage.

Lemma 2. Suppose all $u_{t}^{p}\left(V_{t}\right)$ are linear in $V_{t}$ and bargaining features always-exit strategies $\bar{e}$. Stage $t$ proposer exit payoff $u_{t}^{p}$ and stage $t+1$ continuation value $V_{t+1}$ are determined by the following system of equations:

$$
\begin{gathered}
u_{t}^{p}\left(V_{t}\right)=\frac{1}{2}\left(V_{t}-B C\left(a_{t}, a_{t+1}\right)-\left(u_{t+1}^{p}\right)^{-1}(0)\right) \\
V_{t+1}=\frac{1}{2}\left(V_{t}+L\left(a_{t}\right)+\left(u_{t+1}^{p}\right)^{-1}(0)\right)
\end{gathered},
$$


for $t=0, \ldots, N-1$.

Proof. From Lemma 1, it is straightforward that, at stage $t$, respondent $a_{t}$ leaves the game with a proposer exit payoff

$$
u_{t}^{p}\left(V_{t}\right)=\frac{1}{2}\left(V_{t}-B C\left(a_{t}, a_{t+1}\right)-\left(u_{t+1}^{p}\right)^{-1}(0)\right) .
$$

So, respondent $a_{t+1}$ takes continuation value $V_{t}-C\left(a_{t}, a_{t+1}\right)-w_{t}^{p}$, and

$$
V_{t+1}=\frac{1}{2}\left(V_{t}+L\left(a_{t}\right)+\left(u_{t+1}^{p}\right)^{-1}(0)\right) \text {. }
$$

thus verifying $(1)$.

Equipped with the lemmas, we are now ready to establish the first key properties of the bargaining game.

Proposition 1. In a compromised equilibrium $(R, \bar{e})$ with always-exit strategies, the proposer exit payoff, for $t=0, \ldots, N$, is

$$
u_{t}^{p}=\frac{1}{2}\left(\frac{V_{0}}{2^{t}}+\sum_{s=1}^{t} \frac{L\left(a_{t-s}\right)+\sum_{m=t+1-s}^{N-1} B C\left(a_{m}, a_{m+1}\right)}{2^{s}}-\sum_{s=t}^{N-1} B C\left(a_{s}, a_{s+1}\right)\right) .
$$

Proof. The proof is by backward induction with the use of Lemma 2. These equations are solved from the last stage: At the stage $N-1$, proposer $a_{N-1}$ bargains with respondent $a_{N}$. If this is successful, $a_{N}$ receives $u_{N}^{r}\left(V_{N}\right)=V_{N}$ and the game ends. Notice that $u_{N}^{r}$ is linear and

$$
u_{N-1}^{p}\left(V_{N-1}\right)=\frac{1}{2}\left(V_{N-1}-B C\left(a_{N-1}, a_{N}\right)-\left(u_{N}^{r}\right)^{-1}(0)\right)
$$

is linear in $V_{N-1}$ as well. Thus, we confirm recursively the condition imposed in Lemmas 1 and 2 that each $u_{t}^{p}\left(V_{t}\right)$ is linear in $V_{t}$. From (1) and the terminal exit payoff condition $u_{t}^{p}\left(V_{t}\right)=0$, we have:

$$
\left(u_{t}^{p}\right)^{-1}(0)=B C\left(a_{t}, a_{t+1}\right)+\left(u_{t+1}^{p}\right)^{-1}(0) .
$$

Starting from the last stage $\left(u_{N-1}^{p}\right)^{-1}(0)=B C\left(a_{N-1}, a_{N}\right)$, this solves recursively into

$$
\left(u_{t}^{p}\right)^{-1}(0)=\sum_{s=t}^{N-1} B C\left(a_{s}, a_{s+1}\right)
$$

for $t=0, \ldots, N-1$. Therefore,

$$
u_{t}^{p}\left(V_{t}\right)=\frac{1}{2}\left(V_{t}-B C\left(a_{t}, a_{t+1}\right)-\left(u_{t+1}^{p}\right)^{-1}(0)\right)=\frac{1}{2}\left(V_{t}-\left(u_{t}^{p}\right)^{-1}(0)\right) .
$$


Substituting $V_{0}$ back into $V_{t}$, we have

$$
\begin{aligned}
u_{t}^{p}\left(V_{t}\right) & =\frac{1}{2}\left(V_{t}-\left(u_{t}^{p}\right)^{-1}(0)\right) \\
& =\frac{1}{4}\left(V_{t-1}+L\left(a_{t-1}, a_{t}\right)+\left(u_{t}^{p}\right)^{-1}(0)\right)-\frac{1}{2}\left(u_{t}^{p}\right)^{-1}(0), \\
& =\frac{1}{8}\left(V_{t-2}+L\left(a_{t-2}, a_{t-1}\right)+\left(u_{t-1}^{p}\right)^{-1}(0)\right)+\frac{1}{4} L\left(a_{t-1}, a_{t}\right)+\frac{1}{4}\left(u_{t}^{p}\right)^{-1}(0)-\frac{1}{2}\left(u_{t}^{p}\right)^{-1}(0), \\
& =\cdots \\
& =\frac{1}{2^{t+1}} V_{0}+\sum_{s=0}^{t-1} \frac{L\left(a_{s}\right)+\left(u_{s+1}^{p}\right)^{-1}(0)}{2^{t+1-s}}-\frac{1}{2}\left(u_{t}^{p}\right)^{-1}(0) .
\end{aligned}
$$

Moreover, expanding all $\left(u_{t}^{p}\right)^{-1}(0)$ terms in the above, we can obtain stage $t$ proposer exit payoff as a function of $V_{0}$ as:

$$
\hat{u}_{t}^{p}\left(V_{0}\right)=\frac{1}{2}\left(\frac{V_{0}}{2^{t}}+\sum_{s=1}^{t} \frac{L\left(a_{t-s}\right)+\sum_{m=t+1-s}^{N-1} B C\left(a_{m}, a_{m+1}\right)}{2^{s}}-\sum_{s=t}^{N-1} B C\left(a_{s}, a_{s+1}\right)\right) .
$$

This is $u_{t}^{p}$ in (2).

Remaining characterization of the equilibrium follows. Proposition 2 shows that for any proposer in any proposing order, to exit is always the best response in a compromised equilibrium. Hence, the equilibrium always has everyone proposing once as adopted in Lemmas 1 and 2. Proposition 3 provides the participation constraint for a compromised equilibrium and Theorem 1 presents the characterization of equilibrium. Theorem 2 investigates equilibrium proposing orders. This depends on the form of bargaining costs.

Proposition 2. In a compromised equilibrium $(R, e)$, every proposer exits the game after one stage of bargaining and $p_{t}=a_{t}$.

Proof. Suppose not. Then, in a compromised equilibrium at least one proposer may choose to stay in the game after one round of bargaining.

Suppose the last proposer choosing to stay is at stage $t$. That is $e\left(p_{t}\right)=$ Stay and $e\left(p_{k}\right)=$ Exit for all $k=t+1, \ldots, N-1$. Proposer $p_{t}$ proposes at stages $t$ and $t+1$, then exits afterwards. That is, at first $p_{t}$ carries continuation value $\bar{V}_{t}$ to stage $t$ proposing to $a_{t+1}$. (This proposer $p_{t}$ may not be $a_{t}$, if she proposed before stage $t$ already.) Then, $a_{t+1}$ leaves the game with a respondent payoff $u_{t}^{r}=w_{t}^{r}$, and $p_{t}$ carries proposer worth $\bar{V}_{t+1}=w_{t}^{p}$ to stage $t+1$ proposing to $a_{t+2}$. Use the bar symbols to denote a value already defined in Lemma 2 above but the identity may be assumed by a different agent. For example, stage $t+1$ continuation value $\bar{V}_{t+1}$ is carried over by $p_{t}$ (note that $t$ is a stage label not an identity 
label). Then $p_{t}$ exits with payoff $\bar{u}_{t+1}^{p}$, respondent $a_{t+2}$ continues to stage $t+2$, and will receive exit payoff $u_{t+2}^{p}$. Notice that payoff $u_{t+2}^{p}$ is solved as in the above since all proposers choose to leave from stage $t+2$.

At stage $t+1, p_{t+1}=p_{t}$ carries continuation value $\bar{V}_{t+1}$, spends bargaining $\operatorname{cost} C\left(p_{t}, a_{t+2}\right)$, and proposes to $a_{t+2}$. Because $p_{t}$ proposes twice, the bargaining disagreement point is (- $\left.L\left(p_{t}\right)-C\left(p_{t}, a_{t+2}\right)-C\left(p_{t}, a_{t+1}\right), 0\right)$, where the proposer's payoff is on the horizontal axis and respondent's payoff on the vertical. The bargaining frontier has two end points: Respondent $a_{t+2}$ getting 0 payoff means a worth $\left(u_{t+2}^{p}\right)^{-1}(0)$, and this associates the proposer $p_{t}$ with payoff $\bar{V}_{t+1}-C\left(p_{t}, a_{t+2}\right)-\left(u_{t+2}^{p}\right)^{-1}(0)$. When proposer gets payoff $-L\left(p_{t}\right)-C\left(p_{t}, a_{t+2}\right)-C\left(p_{t}, a_{t+1}\right)$, respondent $a_{t+2}$ is associated with worth $\bar{V}_{t+1}+L\left(p_{t}\right)+$ $C\left(p_{t}, a_{t+1}\right)$. The feasibility set is the triangle composed of $\left(\bar{V}_{t+1}-C\left(p_{t}, a_{t+2}\right)-\left(u_{t+2}^{p}\right)^{-1}(0)\right.$, $0),\left(-L\left(p_{t}\right)-C\left(p_{t}, a_{t+2}\right)-C\left(p_{t}, a_{t+1}\right), u_{t+2}^{p}\left(\bar{V}_{t+1}+L\left(p_{t}\right)+C\left(p_{t}, a_{t+1}\right)\right)\right)$, and the disagreement point. The Nash solution at the circumcenter gives $p_{t}$ stage $t+1$ proposer exit payoff

$$
\bar{u}_{t+1}^{p}\left(\bar{V}_{t+1}\right)=\frac{1}{2}\left(\bar{V}_{t+1}-B C\left(p_{t}, a_{t+2}\right)-C\left(p_{t}, a_{t+1}\right)-\left(u_{t+2}^{p}\right)^{-1}(0)\right) .
$$

The remaining share from $\bar{V}_{t+1}-C\left(p_{t}, a_{t+2}\right)$ left for $a_{t+2}$ is the continuation value

$$
V_{t+2}=\frac{1}{2}\left(\bar{V}_{t+1}+L\left(p_{t}\right)+C\left(p_{t}, a_{t+1}\right)+\left(u_{t+2}^{p}\right)^{-1}(0)\right) .
$$

At stage $t, p_{t}$ carries continuation value $\bar{V}_{t}$, spends bargaining cost $C\left(p_{t}, a_{t+1}\right)$, and proposes to $a_{t+1}$. If this is successful, $a_{t+1}$ leaves the game while $p_{t}$ carries the continuation value $\bar{V}_{t+1}$ into stage $t+1$ and realizes payoff $\bar{u}_{t+1}^{p}\left(\bar{V}_{t+1}\right)$. The disagreement payoff is 0 for $a_{t+1}$ and $-L\left(p_{t}\right)-C\left(p_{t}, a_{t+1}\right)$ for $p_{t}$. From Lemma 1, the feasibility set is thus a right triangle composed of $\left(\bar{u}_{t+1}^{p}\left(\bar{V}_{t}-C\left(p_{t}, a_{t+1}\right)\right)-\left(u_{t}^{r}\right)^{-1}(0), 0\right),\left(-L\left(p_{t}\right)-C\left(p_{t}, a_{t+1}\right), \bar{V}_{t}+L\left(p_{t}\right)\right)$ and the disagreement point $\left(-L\left(p_{t}\right)-C\left(p_{t}, a_{t+1}\right), 0\right)$, whereas solution at the circumcenter gives $p_{t}$ payoff $\left(\bar{u}_{t+1}^{p}\left(\bar{V}_{t}-C\left(p_{t}, a_{t+1}\right)-\left(u_{t}^{r}\right)^{-1}(0)\right)-L\left(p_{t}\right)-C\left(p_{t}, a_{t+1}\right)\right) / 2$, and gives $a_{t+1}$ payoff $u_{t}^{r}=\left(\bar{V}_{t}+L\left(p_{t}\right)\right) / 2$. The remaining share from $\bar{V}_{t}-C\left(p_{t}, a_{t+1}\right)$ after $a_{t+1}$ leaves is a continuation value for $p_{t}$ :

$$
\bar{V}_{t+1}=\frac{1}{2}\left(\bar{V}_{t}-B C\left(p_{t}, a_{t+1}\right)\right)
$$

For a continuation value $\bar{V}_{t}$, proposer $p_{t}$ chooses to stay and propose to $a_{t+2}$ at stage $t+1$ and gets payoff

$$
\bar{u}_{t+1}^{p}\left(\bar{V}_{t+1}\right)=\frac{1}{2}\left(\bar{V}_{t+1}-B C\left(p_{t}, a_{t+2}\right)-C\left(p_{t}, a_{t+1}\right)-\left(u_{t+2}^{p}\right)^{-1}(0)\right) .
$$


Substituting $\bar{V}_{t}$ into $\bar{V}_{t+1}$ in the above, we have the $p_{t}$ 's exit payoff in terms of $V_{t}$ :

$$
\begin{aligned}
\bar{\mu}_{t+1}^{p}\left(\bar{V}_{t}\right) & =\frac{1}{2}\left(\frac{1}{2}\left(\bar{V}_{t^{-}} B C\left(p_{t}, a_{t+1}\right)\right)-B C\left(p_{t}, a_{t+2}\right)-C\left(p_{t}, a_{t+1}\right)-\left(u_{t+2}^{p}\right)^{-1}(0)\right), \\
& =\frac{1}{4}\left(\bar{V}_{t}-B C\left(p_{t}, a_{t+1}\right)\right)-\frac{1}{2} B C\left(p_{t}, a_{t+2}\right)-\frac{1}{2}\left(2 C\left(p_{t}, a_{t+1}\right)+\left(u_{t+2}^{p}\right)^{-1}(0)\right) .
\end{aligned}
$$

Now suppose $p_{t}$ proposes once and exits the game at stage $t$, thus $e\left(p_{t}\right)=$ Exit for all $k=t, \ldots, N-1$. From Lemma 2, her proposer exit payoff at stage $t$ in terms of $\bar{V}_{t}$ is

$$
u_{t}^{p}\left(\bar{V}_{t}\right)=\frac{1}{2}\left(\bar{V}_{t}-L\left(p_{t}\right)-2 C\left(p_{t}, a_{t+1}\right)-\left(u_{t+2}^{p}\right)^{-1}(0)\right) .
$$

Take the difference

$$
u_{t}^{p}\left(\bar{V}_{t}\right)-\bar{\mu}_{t+1}^{p}\left(\bar{V}_{t}\right)=\frac{1}{4}\left(\bar{V}_{t}+B C\left(p_{t}, a_{t+1}\right)+2 B C\left(p_{t}, a_{t+2}\right)\right)>0 .
$$

So, $e\left(p_{t}\right)=$ Stay is not a best response. Therefore, we conclude that $e\left(p_{t}\right)=$ Exit for $t=0, \ldots, N-1$.

The last property is to establish a condition under which every respondent accepts the proposal in a compromised equilibrium. It can be seen below that the condition required turns out to be natural and intuitive.

Condition PC. (Participation Constraint) $1 \geq\left(\sum_{t=0}^{N-1} B C\left(a_{t}, a_{t+1}\right)\right) / V_{0}$.

Proposition 3. In a compromised equilibrium $(R, \bar{e})$, every respondent accepts the proposal under Condition PC.

Proof. We show that $u_{t}^{p}\left(V_{t}\right) \geq 0$ implies $u_{t+1}^{p}\left(V_{t+1}\right) \geq 0$. Suppose $u_{t}^{p}\left(V_{t}\right) \geq 0$, which is equivalent to $V_{t} \geq \sum_{s=t}^{N-1} B\left(a_{s}, a_{s+1}\right)$. Then,

$$
\begin{aligned}
V_{t+1} & =\frac{1}{2}\left(V_{t}+L\left(a_{t}\right)+\sum_{s=t+1}^{N-1} B C\left(a_{s}, a_{s+1}\right)\right) \\
& \geq \frac{1}{2}\left(\sum_{s=t}^{N-1} B C\left(a_{s}, a_{s+1}\right)+L\left(a_{t}\right)+\sum_{s=t+1}^{N-1} B C\left(a_{s}, a_{s+1}\right)\right), \\
& =\sum_{s=t+1}^{N-1} B C\left(a_{s}, a_{s+1}\right)+L\left(a_{t}\right)+C\left(a_{s}, a_{s+1}\right) .
\end{aligned}
$$

Hence, $V_{t+1} \geq \sum_{s=t+1}^{N-1} B C\left(a_{s}, a_{s+1}\right)$, and we have

$$
u_{t+1}^{p}\left(V_{t+1}\right)=\frac{1}{2}\left(V_{t+1}-\sum_{s=t+1}^{N-1} B C\left(a_{s}, a_{s+1}\right)\right) \geq 0 .
$$


Therefore, we only need to check the participation condition for the initiator:

$$
u_{0}^{p}\left(V_{0}\right)=\frac{1}{2}\left(V_{0}-\sum_{s=0}^{N-1} B C\left(a_{s}, a_{s+1}\right)\right) \geq 0 .
$$

This last inequality holds true under Condition PC.

With results from Lemmas 1, 2 and Propositions 1, 2, 3, a full characterization of the compromised equilibrium is presented below.

Theorem 1. In a compromised equilibrium $(R, e)$, the following holds:

(i) Every proposer exits the game after one stage of bargaining (thus, $p_{t}=a_{t}$ ).

(ii) Stage $t$ proposer exit payoff $u_{t}^{p}$ and stage $t+1$ continuation value $V_{t+1}$ are determined by the following system of equations:

$$
\begin{gathered}
u_{t}^{p}\left(V_{t}\right)=\frac{1}{2}\left(V_{t}-B C\left(a_{t}, a_{t+1}\right)-\left(u_{t+1}^{p}\right)^{-1}(0)\right) \\
V_{t+1}=\frac{1}{2}\left(V_{t}+L\left(a_{t}\right)+\left(u_{t+1}^{p}\right)^{-1}(0)\right)
\end{gathered},
$$

for $t=0, \ldots, N-1$.with the last respondent exit payoff $u_{N}^{r}=V_{N}$.

(iii) The proposer exit payoff solves into, for $t=0, \ldots, N$,

$$
u_{t}^{p}=\frac{1}{2}\left(\frac{V_{0}}{2^{t}}+\sum_{h=1}^{t} \frac{L\left(a_{t-h}\right)+\sum_{m=t+1-h}^{N-1} B C\left(a_{m}, a_{m+1}\right)}{2^{h}}-\sum_{h=t}^{N-1} B C\left(a_{h}, a_{h+1}\right)\right) .
$$

(iv) The following participation condition guarantees that every respondent accepts the proposal:

$$
1 \geq\left(\sum_{t=0}^{N-1} B C\left(a_{t}, a_{t+1}\right)\right) / V_{0}
$$

Up to now, we have shown that in a compromised equilibrium with any proposing order, every proposer would exit after one round of bargaining. Hence, everyone proposes once as illustrated in the motivating example. The next question is in what order an equilibrium sequence of bargaining would be. The bargaining configuration turns out to depend on transaction cost and disagreement payoff. Of particularly interest are the monotone bargaining configurations, in that the proposing order is either bottom-up from lowest to highest rank or top-down from highest to lowest.

Proposition 4. Proposing order $R$ constitute an equilibrium bargaining configuration in a compromised equilibrium $(R, \bar{e})$, if and only if it minimizes the total bargaining costs

$$
R \in \arg \min _{R \in \Pi} \sum_{s=0}^{N-1} B C\left(a_{s}, a_{s+1}\right) .
$$


Proof. A proposing order determines the bargaining costs in every agent's payoff. Stage $t$ proposer exit payoff is

$$
\begin{aligned}
\hat{u}_{t}^{p}\left(V_{0}\right) & =\frac{1}{2}\left(\frac{V_{0}}{2^{t}}+\sum_{s=1}^{t} \frac{L\left(a_{t-s}\right)+\sum_{m=t+1-s}^{N-1} B C\left(a_{m}, a_{m+1}\right)}{2^{s}}-\sum_{s=t}^{N-1} B C\left(a_{s}, a_{s+1}\right)\right), \\
& =\frac{1}{2}\left(\frac{V_{0}}{2^{t}}+\sum_{s=1}^{t} \frac{L\left(a_{t-s}\right)+\sum_{m=t+1-s}^{t-1} B C\left(a_{m}, a_{m+1}\right)}{2^{s}}\right)+\frac{\sum_{s=1}^{t} \frac{1}{2^{s}}-1}{2} \sum_{s=t}^{N-1} B C\left(a_{s}, a_{s+1}\right) .
\end{aligned}
$$

The bargaining sequence from agent $a_{t}$ afterwards, stage $t$ to stage $N-1$, only affects the second term in the above expression, where stage bargaining costs show up with equal weights. Therefore, every stage $t$ proposer's best response is to minimize the sum of continuation bargaining costs $\sum_{s=t}^{N-1} B C\left(a_{s}, a_{s+1}\right)$. If $R$ is a subgame perfect equilibrium, bargaining costs $\sum_{s=t}^{N-1} B C\left(a_{s}, a_{s+1}\right)$ is minimized for the proposer at each stage $t$, including the initiator.

Denote the bargaining costs following proposing order $R$ as $B C^{R}\left(a_{t}, a_{t+1}\right)$. Actually, if proposing order $R$ is a minimizer to the initiator's problem $\min _{R \in \Pi} \sum_{s=0}^{N-1} B C\left(a_{s}, a_{s+1}\right)$, it is a subgame perfect equilibrium. Suppose not, there is a stage $k$ proposer proposing to another rank $R^{\prime}\left(a_{k+1}\right)$. This deviation generates for the subgame from stage $k$ another bargaining sequence: $R^{\prime}\left(a_{k+1}\right), \ldots, R^{\prime}\left(a_{N}\right)$. Then, $\sum_{s=k}^{N-1} B C^{R^{\prime}}\left(a_{s}, a_{s+1}\right)$ must be lower than $\sum_{s=t}^{N-1} B C^{R}\left(a_{s}, a_{s+1}\right)$, and the sum

$$
\sum_{s=0}^{k-1} B C^{R}\left(a_{s}, a_{s+1}\right)+\sum_{s=k}^{N-1} B C^{R^{\prime}}\left(a_{s}, a_{s+1}\right)<\sum_{s=0}^{N-1} B C^{R}\left(a_{s}, a_{s+1}\right) .
$$

So, $R$ is not a bargaining costs minimizer for the initiator; a contradiction.

Consider:

Condition PC1. (Participation Constraint) $1 \geq\left(\pi \sum_{s=0}^{N-1} l(s)+2 N \cdot c(1)\right) / V_{0}$.

With this, the following proposition will establish that with the benchmark setting of increasing $l$ and weakly convex $c$, the unique bargaining configuration is to go from bottom up.

Theorem 2. Under Condition PC1, there is a unique compromised equilibrium with a bottom-up proposing order. The initiator proposes to the bottom rank agent and each agent proposes to the agent ranked immediately above.

Proof. Equilibrium proposing orders are minimizers of total bargaining costs $\sum_{s=0}^{N-1} B C\left(a_{s}, a_{s+1}\right)$. The sum of disagreement losses $\sum_{s=0}^{N-1} L\left(a_{s}\right)$ contains all agents but the last respondent. This 
sum of losses can be minimized if the highest rank remains the last into bargaining. The cost terms are positive when agents propose upward in rank. However, the order needs to go all the way up to the highest rank in order to cover all agents. A jump in rank incurs no less costs than going up the rank one by one due to convexity of $c$. The bottom-up order yields a sum of transaction $\operatorname{costs} 2 N \cdot c(1)$, and the losses sum to $\pi \sum_{s=0}^{N-1} l(s)$. There is no other order that brings lower bargaining costs. Condition PC1 follows.

In practice, bottom-up bargaining sequence has been common in corruption case studies. This is particularly so due to the hierarchical structure of the organization. For example, in the case of Aceh trucking studied in Olken and Barron (2009), the bribing sequence is by design starting from the lowest levels at checkpoints and weigh stations. In the case where the local government investigates citizens' compliance with regulations examined by Angelucci and Russo (2022), bribes also begin with officials at the lowest level in the authority. Our results suggest that under the most natural convex transaction cost structure, bottom-up order always arises as long as the value of the deal is sufficiently large for these decisionmakers to find it worth the risk of being detected.

When the potential value from the deal is not large enough, so that the participation condition does not hold, bargaining breaks down. An obvious factor is that there are too many players to share the deal. Yet, the size factor can be isolated with assuming the value of the deal to be proportional to player population. With a constant per capita value, if bargaining still beaks down with size, the cause is then the length of the chain. For simplicity, a loss function proportional to the rank is also assumed in Corollary 1: $l(s)=q s$ and $V_{0}=v N$ where $q>0$ and $v>0$ are constant. It is shown that when the chain is long, bargaining breaks down.

Corollary 1. With proportional $l$ and a constant per capita value $v$, a compromised equilibrium does not exist if $N>\frac{2}{\pi q}(v-2 c(1))+1$.

Proof. PC1 requires $v \geq\left(\frac{(N+1)}{2}-1\right) \pi q+2 c(1)$. So, if

$$
N>\frac{2}{\pi q}(v-2 c(1))+1,
$$

the initial value is not large enough to sustain the sequence of bargains.

When the equilibrium does not exist, it corresponds to the case of bargaining breakdown in Blanchard and Kreamer (1997). In our benchmark setting, breakdown occurs when the length $(N)$ on the chain of the authority is too long, which reconfirms the property obtained 
in Blanchard and Kreamer (1997). Moreover, by examining the condition in Corollary 1, it can be seen that bargaining is more likely to break down if detection probability $(\pi)$ is too high, the transaction cost scale $(c(1))$ is too large, or the per capita value of the deal $(v)$ is not large enough.

\section{Bargaining Configurations under Alternative Setting}

Theorem 2 establishes the bottom-up bargaining configuration that is commonly observed in practice. The benchmark assumptions of increasing $l$ and weakly convex $c$, as specified in Assumptions 1 and 2, covers a broad and realistic parameter range, which includes situations when authority agents have increasing information cost getting to know each other farther across the organization. The opposite top-down proposing order may be an equilibrium, where the initiator proposes to the top rank agent and then each agent proposes to the agent ranked immediately below. A strictly concave cost function helps to reduce transaction costs when taking the highest rank first, instead of going up the rank one by one. A non-monotonic configuration may also be in equilibrium - the second-man-first order: the initiator proposes to the second highest rank $N-1$, then bargaining goes down by rank to the lowest, at the last stage rank 1 proposes up to rank $N$. Compared to the top-down order, the extra transaction cost at the last stage is for reducing the loss associated with rank $N$. These two orders can emerge in equilibrium when disagreement losses are proportional and transaction costs are strictly concave, as presented in Proposition 5.

Two remarks on these alternative proposing sequences in practice are in order. First, the top-down configuration has been frequently observed when institutions are not wellestablished. For example, the case of tunneling in Moscow government procurement allocation to Inteko analyzed by Mironov and Zhuravskaya (2016) indicates the initial proposal from Inteko went to the former Moscow mayor directly who subsequently worked out the deal with his subordinates. Second, another configuration with the second man being approached first by the initiator has also been observed. For instance, as illustrated by Bai, Hsieh, and Song (2016), China's local government allocation of central government investment projects often featured a local business approaching the second highest local official (non-party leader vice governors or vice majors), who serves as the "frontman" (or the gatekeeper) to protect the top official from being detected. Although the process of the remaining bargaining configuration is not fully specified in their study, one may expect two types of orders: the frontman may take the deal directly to the top local official (party leader) in the next round 
or work out a deal with all the subordinates before taking it to the top ranked. The general case of such configurations can also be captured in our setting with an adjusted transaction cost function, which will be discussed in Corollary 3 .

Formally, we shall establish indifference boundaries between different proposing orders based on total bargaining costs. The bargaining costs for the bottom-up, the top-down, and the second-man-first orders are denoted by $B C B, B C T$, and $B C S$ respectively, listed below:

$$
\begin{aligned}
B C B & =\pi\left(\sum_{s=0}^{N} l(s)-l(N)\right)+2 N \cdot c(1) . \\
B C T & =\pi\left(\sum_{s=0}^{N} l(s)-l(1)\right)+2 c(N) . \\
B C S & =\pi\left(\sum_{s=0}^{N} l(s)-l(N)\right)+4 c(N-1) .
\end{aligned}
$$

Consider.

Condition PC2. (Participation Constraint) $1 \geq B C T / V_{0}$.

Condition PC3. (Participation Constraint) $1 \geq B C S / V_{0}$.

Proposition 5. With proportional $l$ and strictly concave $c$, the proposing order in a compromised equilibrium is

(i) the bottom-up order when $B C B \leq B C T, B C B \leq B C S$ and $P C 1$ are satisfied;

(ii) the top-down order when $B C B \geq B C T, B C T \leq B C S$ and $P C 2$ are satisfied;

(iii) the second-man-first order when $B C B \geq B C S, B C T \geq B C S$ and PC3 are satisfied.

Proof. Besides the bottom-up order, all other proposing orders which are candidates for minimizers of the total bargaining costs are discussed below. Suppose rank $K$ is left for the last stage. To utilize zero transaction costs down the rank, bargaining has two viable ways:

First, the initiator starts with rank 1 , then bargaining goes up one by one to rank $K-1$. Then rank $K-1$ proposes to rank $N$, and then goes down to rank $K$. The associated bargaining costs are

$$
\pi \sum_{s=0}^{N} l(s)-\pi l(K)+2((K-1) c(1)+c(N-K+1)) .
$$

The term $-\pi l(K)+2((K-1) c(1)+c(N-K+1))$ is concave in $K$. The minimum values happen at rank $K=1$ (top-down) or $K=N$ (bottom-up). 
Second, the initiator starts with rank $K-1$, then bargaining goes down one by one to rank 1 , then rank 1 proposes to rank $N$, then bargaining goes down to rank $K$. The associated bargaining costs are

$$
\pi \sum_{s=0}^{N} l(s)-\pi l(K)+2(c(N-1)+c(K-1)) .
$$

Notice that the term $-\pi l(K)+2 c(K-1)$ is concave in $K$, the minimum values happen at $K=N$ (second-man-first) or $K=2$ (called bottom-second-last), where the initiator proposes to rank 1 , then rank 1 proposes to rank $N$, then bargaining goes down one by one by rank, and ends with rank 2 .

Other orders that ends with rank $K$ have higher costs than the above two cases. For example, the initiator may propose to rank $N$, then bargaining goes down one by one, but skipping rank $K$. At the last stage, rank 1 proposes to rank $K$. The associated bargaining costs is $2(c(N)+c(K-1))$, for sure larger than the first case. If the initiator proposes to a rank higher than $K$, or if the initiator proposes to a rank lower than $K-1$, breaking the rank jump into steps, the cost will be higher than the first case by concavity.

Actually, only bottom-up, top-down, and second-man-first are possible bargaining costs minimizers. The bottom-second-last order cannot be a minimizer. Denote its total bargaining costs by $B C L=\pi \sum_{s=0}^{N} l(s)-\pi l(2)+2(c(1)+c(N-1))$. For this order to be a minimizer, $B C B \geq B C L$ and $B C T \geq B C L$ need to hold together, which means the following two inequalities respectively:

$$
\begin{aligned}
2((N-1) c(1)-c(N-1)) /(N-2)-\pi(l(N)-l(2)) /(N-2) & \geq 0 \\
2(c(N)-c(1)-c(N-1))-\pi(l(1)-l(2)) & \geq 0 .
\end{aligned}
$$

They sum to $(N-2) c(N)+c(1)-(N-1) c(N-1) \geq 0$, which violates strict concavity.

The comparison of bargaining costs are listed below:

$$
\begin{aligned}
B C B & \leq B C T \Longleftrightarrow 2(N c(1)-c(N))-\pi(l(N)-l(1)) \leq 0, \\
B C B & \leq B C S \Longleftrightarrow N c(1)-2 c(N-1) \leq 0 \\
B C T & \leq B C S \Longleftrightarrow 2(c(N)-2 c(N-1))-\pi(l(1)-l(N)) \leq 0,
\end{aligned}
$$

which completes the proof.

The length of the chain causes bargaining to break down in the benchmark setting. Proposition 6 examines the setting with a concave $c$, and shows that when the population is 
sufficiently large, a compromised equilibrium fail to exist due to length of the chain. Moreover, the trade-offs between equilibrium proposing orders are affected as well. The bottom-up order and the second-man-first order will vanish from equilibrium with a sufficiently large population.

Proposition 6. Assume strictly concave transaction cost $c(r)$, proportional disagreement loss $l(s)=q s$ with $q>0$, and a constant per capita value of the deal $v=V_{0} / N$. When $N$ is sufficiently large, sequential bargaining features:

(i) no compromised equilibrium if $N>1+\frac{2}{\pi q}\left(v-2 c(1) \min \left\{1, \frac{2 c(N-1)}{N c(1)}\right\}\right)$;

(ii) no bottom-up order in equilibrium if $N c(1)-c(N) \geq q(N-1) / 2$ given $\lim _{N \rightarrow \infty} c^{\prime}(N)<$ $c(1)-\frac{q}{2} ;$ or

(iii) no second-man-first order in equilibrium if $2 c(N-1)-c(N) \geq q(N-1) / 2$ given $\lim _{N \rightarrow \infty} c^{\prime}(N)>\frac{q}{2}$.

Proof. (i) PC1, PC2 and PC3 require $v \geq\left(\frac{(N+1)}{2}-1\right) \pi q+2 c(1), v \geq\left(\frac{(N+1)}{2}-\frac{1}{N}\right) \pi q+$ $\frac{2 c(N)}{N}$ and $v \geq\left(\frac{(N+1)}{2}-1\right) \pi q+\frac{4 c(N-1)}{N}$ respectively. Take a combination of minimums:

$$
v \geq\left(\frac{(N+1)}{2}-1\right) \pi q+2 \min \left\{c(1), \frac{2 c(N-1)}{N}\right\},
$$

which holds if any of the three participation conditions holds. So, if

$$
N>1+\frac{2}{\pi q}\left(v-2 \min \left\{c(1), \frac{2 c(N-1)}{N}\right\}\right)
$$

all three equilibrium breaks down due to insufficient value from the deal. Note that $\lim _{N \rightarrow \infty}$ $\frac{2 c(N-1)}{N}=2 \lim _{N \rightarrow \infty} c^{\prime}(N)<2 c(1)$ is bounded.

(ii) and (iii) The requirements on $\pi$ in the comparison of total bargaining costs are given by $\pi \geq B T \equiv \frac{2(N c(1)-c(N))}{q(N-1)}$ for $B C B \leq B C T$, and $\pi \leq T S \equiv \frac{2(2 c(N-1)-c(N))}{q(N-1)}$ for $B C T \leq$ $B C S$. Taking limits for $N \rightarrow \infty$ and using L'Hôpital's rule, we have: $\lim _{N \rightarrow \infty} \frac{N c(1)}{c(N)}=$ $\lim _{N \rightarrow \infty} \frac{c(1)}{c^{\prime}(N)}>1$, where the last inequality holds because concavity implies the slope of $c$ is bounded by $c(1)$. Noting also, $c^{\prime}>0$, we have: (a) $\lim _{N \rightarrow \infty} B T=\lim _{N \rightarrow \infty} \frac{2\left(c(1)-c^{\prime}(N)\right)}{q}>0$, (b) $\lim _{N \rightarrow \infty} T S=\lim _{N \rightarrow \infty} \frac{2 c^{\prime}(N)}{q}<\frac{2 c(1)}{q}$, which is bounded. Then as $N$ becomes sufficiently large, two of the equilibrium conditions will move outside the range of $\pi \in(0,1)$. Specifically, $\pi \geq 1$ if $\lim _{N \rightarrow \infty} B T \geq 1$, which means $\lim _{N \rightarrow \infty} c^{\prime}(N) \leq c(1)-\frac{q}{2}$, or if $\lim _{N \rightarrow \infty} T S \geq 1$, which means $\lim _{N \rightarrow \infty} c^{\prime}(N) \geq \frac{q}{2}$. That is, the bottom-up order cannot be in equilibrium if (1) given $\lim _{N \rightarrow \infty} c^{\prime}(N)<c(1)-\frac{q}{2}, B T \geq 1$ which means $N c(1)-c(N) \geq q(N-1) / 2$. 
The second-man-first order cannot be an equilibrium if, given $\lim _{N \rightarrow \infty} c^{\prime}(N)>q / 2$, $T S \geq 1$ which means $2 c(N-1)-c(N) \geq q(N-1) / 2$.

The breakdown condition in Proposition 6.(i) extends that in Corollary 1 to the alternative setting. It is more likely to hold if per capita value of the deal $v$ is low, detection probability $\pi$ is high, and the transaction cost scale $c(1)$ is large, similar to the benchmark case. In addition, the curvature of $c$ matters as well when $\frac{2 c(N-1)}{N c(1)}<1$. Because $\lim _{N \rightarrow \infty} \frac{2 c(N-1)}{N}=\lim _{N \rightarrow \infty} 2 c^{\prime}(N)$, breakdown condition is more likely to occur if the marginal transaction cost $c^{\prime}(N)$ is large, for example, if $c$ is overall less concave.

Under the same assumptions in Proposition 6, one may further establish that top-down can emerge in equilibrium in spite of large $N$. This is because of minimizing concave transaction cost under the top-down configuration.

Corollary 2. Assume strictly concave transaction cost $c(r)$, proportional disagreement loss $l(s)=q s$ with $q>0$, and a constant per capita value of the deal $v=V_{0} / N$. When $N$ is sufficiently large, sequential bargaining features the top-down order in equilibrium for values of $\pi \leq \frac{2}{q} \min \left\{\frac{N c(1)-c(N)}{N-1}, \frac{2 c(N-1)-c(N)}{N-1}, \frac{v N-2 c(N)}{N(N+1)-2}\right\}$, given $v>2 c(N) / N$.

Proof. The top-down order requires $\pi \leq B T$ and $\pi \leq T S$ in equilibrium. These can always hold for small values of $\pi \in(0,1)$ when $N$ is large, since $B T>0$ and $\lim _{N \rightarrow \infty} T S>0$. PC2 requires $v \geq \pi q\left(\frac{(N+1)}{2}-\frac{1}{N}\right)+\frac{2 c(N)}{N}$, so $\pi \leq\left(v-\frac{2 c(N)}{N}\right) \frac{2 N}{(N(N+1)-2) q}$. Thus, a value of $\pi$ no larger than $\frac{2}{q} \min \left\{\frac{N c(1)-c(N)}{N-1}, \frac{2 c(N-1)-c(N)}{N-1}, \frac{N}{N(N+1)-2}\left(v-\frac{2 c(N)}{N}\right)\right\}$ together with $v>$ $2 c(N) / N$ can support an equilibrium.

As discussed above, the non-monotonic configuration with the second man going first is observed in practice. This is but one of the variations of the configuration with a middle rank being proposed first. In some organizations, a few higher rank agents may form an "insider group" that is not easily accessible to outside initiators or lower rank agents. Yet, there is a frontman who is in charge of outside contacts and handling any sensitive issue that may potentially put the insider group at risk. Under this circumstance, the frontman needs to be proposed first before the deal can be passed onto the insider group. Facing an accessible frontman of rank $K<N$, the outsider transaction cost has a discrete jump before the frontman has been proposed:

$$
\hat{C}\left(p_{t}, a_{t+1}\right)=\left\{\begin{array}{ll}
c\left(r_{r}\right) & \text { for } R\left(a_{t+1}\right) \leq K \\
c\left(r_{r}\right)+F & \text { for } R\left(a_{t+1}\right)>K
\end{array},\right.
$$

where $F$ is a prohibitively high cost for accessing a higher rank insider. After rank $K$ 
frontman is proposed, insiders would know about the deal and the transaction cost returns to $c$. We are thus arrived at the following property.

Corollary 3. Assume strictly concave c, outsider transaction cost $\hat{C}$, and proportional disagreement loss l, bargaining may start with middle rank $K<N$ in a compromised equilibrium.

Proof. Among the candidates for equilibrium proposing orders in Proposition 5, topdown and second-man-first are affected by outsider cost $\hat{C}$. Letting rank $K$ being proposed first before going to the top in the top-down order, the total bargaining cost is $B C K 1=\pi \sum_{s=0}^{N} l(s)-\pi l(1)+2(c(K)+c(N-K))$. Letting rank $K$ being proposed first before going to the second highest in the second-man-first order, the total bargaining cost is $B C K 2=\pi \sum_{s=0}^{N} l(s)-\pi l(N)+2(c(K)+c(N-K-1)+c(N-1))$. Note that this order is second-man-first when $K=N-1$. And the bottom-second-last order has total bargaining cost $B C L^{\prime}=\pi \sum_{s=0}^{N} l(s)-\pi l(2)+2(c(1)+c(K-1)+c(N-K))$ since rank 1 needs to propose to rank $K$ first. When $\min \{B C K 1, B C K 2\} \leq \min \left\{B C B, B C L^{\prime}\right\}$, the initiator proposes to rank $K$ first.

When the second highest rank is the frontman, $K=N-1$, two orders could be in equilibrium including previously defined second-man-first order. The other one, which is modified from top-down, will be called "second-man-then-top," with the second man being proposed first immediately followed by the top ranked insider in the next round. They are illustrated by numerical examples in the following.

Numerical Range for Bargaining Configurations While general properties have been proved in Theorem 2, Propositions 5 and 6, and Corollaries 1 and 2 above, it is informative to illustrate graphically when different bargaining configurations arise in equilibrium under a combination of parameter values. The main element determining the bargaining configuration is the bargaining cost: $B C\left(a_{t}, a_{t+1}\right)=\pi \cdot l(s)+2 c(r)$ when $r>0$, or $\pi \cdot l(s)$ when $r \leq 0$. where $s=R\left(a_{t}\right)$ and $r=R\left(a_{t+1}\right)-R\left(a_{t}\right)$. Consider a linear function for the disagreement loss and a power function for the transaction cost: $\pi l(s)=\pi q s$ and $c(r)=r^{1 / \lambda}$, where, in addition to detection probability measured by $\pi \in(0,1)$ and a disagreement loss scaling parameter $q>0$, we have most crucially a curvature parameter for the transaction cost $\gamma>0$. Thus, $c(r)$ is weakly convex if $\gamma \in(0,1]$ and strictly concave if $\gamma>1$. For illustrative purposes, we focus on determining bargaining configurations in the $(\gamma, \pi)$ space. We set $q=5, N=5$ so the largest rank different is $\max \{r\}=5$, and $V_{0}=50$ so $v=10$. While the 


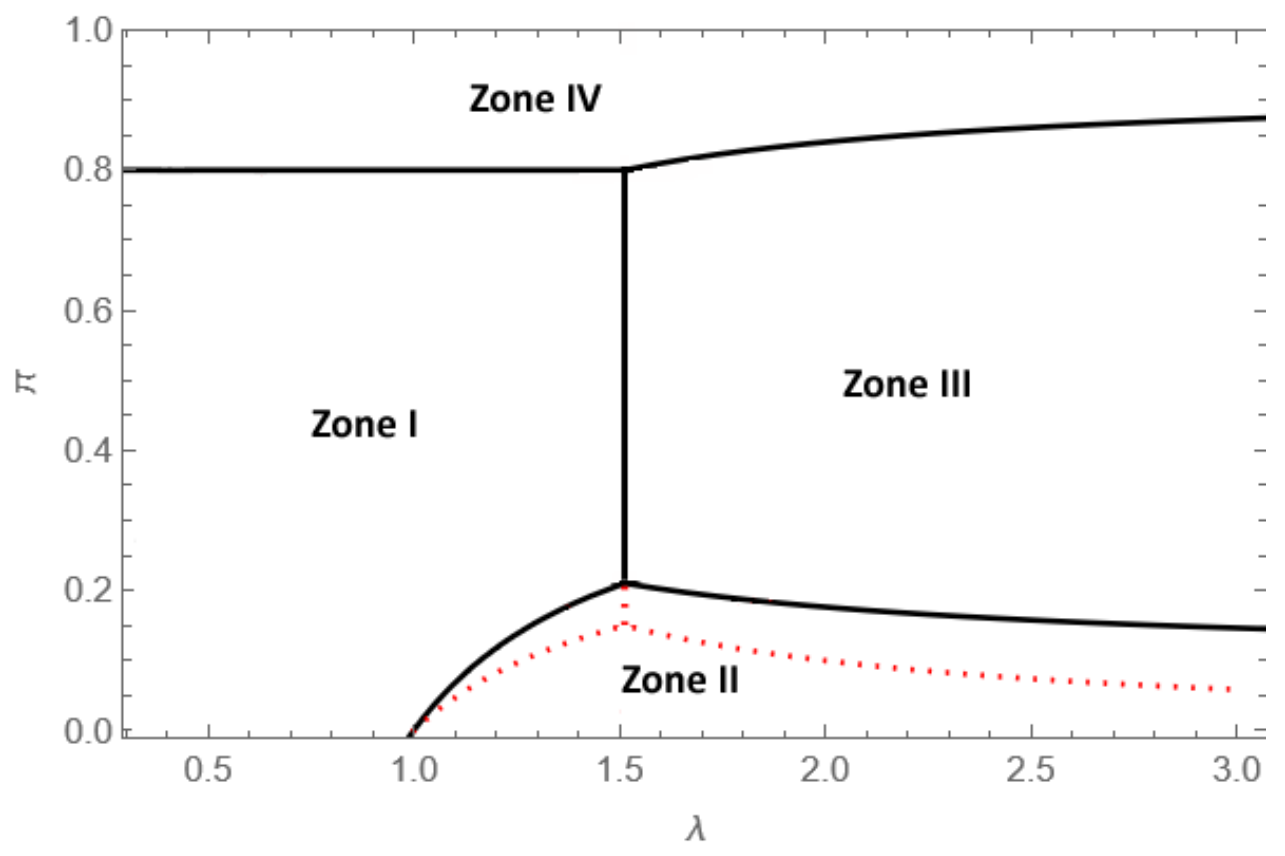

Figure 2: Equilibrium proposing orders.

detail of this example is relegated to Appendix I, it is noted that, from Theorem 1, under $\gamma \in(0,1]$ only bottom-up may arise in equilibrium. The parameter ranges for equilibrium proposing orders are plotted as solid curves in Figure 2 over the ranges of $\lambda \in[0.3,3]$ and $\pi \in[0,1]$.

Thus, based on solid borders, we have: (i) Zone I: Bottom-up, (ii) Zone II: Top-down, (iii) Zone III: Second-man-first, and (iv) Zone IV: No equilibrium. While the kinked border separating Zone IV from Zones 1 and 2 represents the respective participation constraints given in Conditions PC1 and PC3, those separating the three equilibrium zones, Zone I, Zone II and Zone III, are all pairwise indifferent boundaries that capture $B C B=B C T$, $B C B=B C S$, and $B C T=B C S$. When $\lambda \in[0.3,1], c$ is weakly convex, and bottom-up is the unique equilibrium order. When $\lambda>1, c$ is strictly concave, and all three orders are possible equilibria in different parameter ranges. As $c$ becomes more concave, for example, its curvature increases passing $\gamma=1.513$, the bottom-up order no longer arises in equilibrium; only top-down and second-man-first orders remain as candidates for equilibrium, with the non-monotonic configurations emerging when detection probability is relatively high but not too high to meet the participation constraint. In this range, rank jumps yield significant cost reductions. In Zone IV, no equilibrium exists as participation constraints are violated, where bargaining breaks down.

Bargaining within an organization with a frontman, as in Corollary 3, is also depicted 
in Figure 2 by modifying the indifference boundaries with dotted curves. In addition to the above parametrization, we add an outsider transaction cost function with $K=4$ and $F \geq 5$, with the second highest rank (rank 4) as the frontman. Three types of equilibrium configurations exist in zones modified by dotted curves. With the frontman, the bottom-up and the second-man-first (or, more precisely, second-man-then-down) configurations remain, but the top-down order needs to go through the second highest rank first and becomes the secondman-then-top order. Under this modified setting, Zone IV (no equilibrium) stays unchanged as participation constraints PC1 and PC3 are the same; moreover, the indifferent boundary between Zones I (bottom-up) and III (second-man-first) does not change. Yet, Zones I and III expand into Zone II (below dotted borders), where this alternative second-man-thentop order replaces the previous top-down order in the absence of a frontman. Notably, the second-man-then-top order incurs a higher total transaction cost than the original top-down order because the deal must pass through the frontman first. This explains why the indifference boundaries between Zone II and Zone I and Zone III shift downward and hence Zone II shrinks. The possibility for both second-man-then-top (Zone II) and second-man-first (Zone III) to arise in equilibrium indicates rich non-monotonic bargaining configurations, capturing the situation described in Bai, Hsieh, and Song (2016).

\section{Conclusions}

In this paper, we modeled back-door negotiation with group corruption and examined the role played by the architecture of a multi-tier authority and the endogenously determined sequence of bargains. We have established sufficient conditions under which the most natural bottom-up bargaining configuration arises in equilibrium. We have also explored more generally the top-down and a non-monotonic configuration.

While bargaining among a strict ordering of ranks, in a chain hierarchy, is investigated throughout the main text, we would like to note that it is straightforward to generalize the analysis to multi-tier authorities with multiple agents of the same rank in each tier such as in a tree hierarchy. This generalization is of interest because, in the Aceh trucking case studied in Olken and Barron (2009), checkpoints and weigh stations are, respectively, controlled by two groups of decision-makers, namely police/military units and local governments, which are arguably of equal rank in monitoring truck maximum loading. As shown in the Appendix

II, the set of equilibrium configurations may become large containing more non-monotone bargaining sequences. 
Along the lines of this research, it may be of interest to further study the role of incomplete information and hence incomplete contract played in the bargaining process, a structure frequently adopted in previous studies of corruption. It may also be productive to explore, when considering a government or legislation hierarchy, the role of political economy and voting in inducing various bargaining configurations and equilibrium outcomes. In both extensions, one may also conduct normative analysis, investigating the welfare consequences of corruption, particularly whether corruption causes inefficiency through misallocation or becomes efficient grease to ease institutional barriers. These, while beyond the scope of the current paper, are possible avenues for future work.

\section{References}

[1] Aghion, Philippe and Jean Tirole, "Formal and Real Authority in Organizations," Journal of Political Economy 105 (February 1997), 1-29.

[2] Aidt, Toke S., "Economic Analysis of Corruption: A Survey," Economic Journal 113 (November 2003), F632-F652.

[3] Angelucci, Charles and Antonio Russo, "Petty Corruption and Citizen Reports," International Economic Review (forthcoming 2022).

[4] Arrow, Kenneth J., The Limits of Organization, Norton, New York, NY, 1974.

[5] Bac, Mehmet, "Corruption, Supervision and the Structures of Hierarchies," Journal of Law, Economics and Organization, 12 (October 1996), 277-298.

[6] Bag, Parimal K., "Controlling Corruption in Hierarchies," Journal of Comparative Economics, 25 (December 1997), 322-344.

[7] Bai, Chong-En, Chang-Tai Hsieh, and Zheng Michael Song, "The Long Shadow of a Fiscal Expansion," Working Paper, University of Chicago.

[8] Banerjee, Abhijit V., "A Theory of Misgovernance," Quarterly Journal of Economics 112 (December 1997), 1289-1332.

[9] Bardhan, Pranab, "Corruption and Development: A Review of Issues," Journal of Economic Literature 35 (December 1997), 1320-1346.

[10] Baron, David P. and John A. Ferejohn, "Bargaining in Legislatures," American Political Science Review 83 (December 1989), 1181-1206.

[11] Blanchard, Olivier and Michael Kremer, "Disorganization," Quarterly Journal of Economics 112 (December 1997), 1091-1126.

[12] Bolton, Patrick and Mathias Dewatripont, "The Firm as a Communication Network," Quarterly Journal of Economics 109 (August 1994), 809-839. 
[13] Cingano, Federico and Paolo Pinotti, "Politicians at Work: The Private Returns and Social Costs of Political Connections," Journal of European Economic Association 11 (April 2013), 435-465.

[14] Eraslan, Hülya and Andrew McLennan, "Uniqueness of Equilibrium Payoffs in Coalitional Bargaining," Journal of Economic Theory 148 (November 2013), 2196-2222.

[15] Friedenberg, Amanda, "Bargaining under Strategic Uncertainty: The Role of SecondOrder Optimism," Econometrica 87(6) (November 2019), 1835-1865.

[16] Hurwicz, Leonid, "But Who Will Guard the Guardians?" Nobel Prize Lecture, Stockholm, December 8, 2007.

[17] Klitgaard, Robert, Controlling Corruption, University of California-Berkeley, CA, 1988.

[18] Kofman, Fred and Jacques Lawarrée, "Collusion in Hierarchical Agency," Econometrica, 61 (May 1993), 629-656.

[19] Laffont, Jean-Jacques and Jean Tirole, "The Politics of Government Decision Making: Regulatory Institutes," Journal of Law, Economics and Organization, 6 (January 1990), $1-31$.

[20] Levine, David K. and Salvatore Modica (2016), "Peer Discipline and Incentives Within Groups," Journal of Economic Behavior \& Organization 123 (March 2016) 19-30.

[21] Mauro, Paolo, "Corruption and Growth," Quarterly Journal of Economics, 110 (August 1995), 681-712.

[22] Melumad, Nahum D., Dilip Mookherjee and Stefan Reichelstein, "Hierarchical Decentralization of Incentive Contracts," Rand Journal of Economics, 26 (Winter 1995), 654672 .

[23] Mironov, Maxim and Ekaterina Zhuravskaya, "Corruption in Procurement and the Political Cycle in Tunneling: Evidence from Financial Transactions Data," American Economic Journal: Economic Policy 8 (May 2016), 287-321.

[24] Mookherjee, Dilip and I.P.L. Png, "Corruptible Law Enforcers: How Should They Be Compensated," Economic Journal, 105 (January 1995), 145-159.

[25] Muthoo, Abhinay, Bargaining Theory with Applications, Cambridge University Press, Cambridge, MA, 1999.

[26] Nash, John. "The Bargaining Problem," Econometrica, 18 (1950), 155-162.

[27] Olken, Benjamin A. and Patrick Barron, "The Simple Economics of Extortion: Evidence from Trucking in Aceh," Journal of Political Economy, 117 (June 2009), 417-452.

[28] Radner, Roy, "Hierarchy: The Economics of Managing," Journal of Economic Literature, 30 (September 1992), 1382-1415.

[29] Rose-Ackerman, Susan, Corruption: A Study of Political Economy, Academic Press, New York, NY, 1978. 
[30] Rose-Ackerman, Susan, "The Political Economy of Corruption," in Kimberly Ann Elliott (ed.), Corruption and the Global Economy, Institute for International Economics, Washington, DC, 1996, 31-60.

[31] Rosen, Sherwin, "Authority, Control and the Distribution of Earnings," Bell Journal of Economics, 13 (Autumn 1982), 311-323.

[32] Rubinstein, Ariel, "Perfect Equilibrium in a Bargaining Model," Econometrica, 50 (January 1982), 97-108.

[33] Sah, Raaj K. and Joseph E. Stiglitz, "The Architecture of Economic Systems: Hierarchies and Polyarchies," American Economic Review, 76 (September 1986), 716-727.

[34] Shleifer, Andrei and Robert W. Vishny, "Corruption," Quarterly Journal of Economics, 108 (August 1993), 599-617.

[35] Strulovici, Bruno, "Learning and Corruption on Monitoring Chains," American Economic Association Papers and Proceedings 111 (May 2021), 544-548.

[36] Tirole, Jean, "Collusion and the Theory of Organizations," in Jean-Jacques Laffont, ed., Advances in Economic Theory, (The Sixth World Congress of the Econometric Society), Cambridge University Press, Cambridge, UK, 1992, 151-206.

[37] Tirole, Jean, "A Theory of Collective Reputations (with Applications to the Persistence of Corruption and to Firm Quality)," Review of Economic Studies 63 (January 1996), $1-22$.

[38] Tsai, Tsung-Sheng and C. C. Yang, "On Majoritarian Bargaining With Incomplete Information," International Economic Review 51 (November 2010), 959-979.

[39] Tullock, Gordon, Economic Hierarchies, Organization and the Structure of Production, Kluwer Academic: Norwell, MA, 1992.

[40] Williamson, Oliver E., Markets and Hierarchies, Free Press, New York, NY, 1975. 


\section{Appendix I: Numerical Range for Bargaining Configu- rations (Not Intended for Publication)}

Under the disagreement loss and transaction cost functions specified above, we have the following boundary characterization between equilibrium orders for the numerical exercise:

$$
\begin{aligned}
B C B & \leq B C T \Longleftrightarrow \pi \geq \frac{2}{q} \frac{N-N^{1 / \lambda}}{N-1} \equiv \Lambda_{B T}(\lambda) \\
B C T & \leq B C S \Longleftrightarrow \pi \leq \frac{2}{q} \frac{2(N-1)^{1 / \lambda}-N^{1 / \lambda}}{N-1} \equiv \Lambda_{T S}(\lambda) .
\end{aligned}
$$

Theorem 1 shows $B C B<B C T$ when $c(r)$ is weakly convex, i.e., $\gamma \in(0,1]$. This enables us to focus primarily on strictly concave transaction costs for other orders. Particularly, when $\gamma>1, \Lambda_{B T}(\lambda)$ is strictly increasing and strictly concave, whereas $\Lambda_{T S}(\lambda)$ is nonincreasing and its second derivative is generally ambiguous, depending on the sign of $\Xi$ where

$\Xi(\lambda) \equiv\left((\log (N))^{2} N^{1 / \lambda}-(\log (N-1))^{2}(N-1)^{1 / \lambda}\right)-2 \lambda\left(\log (N) N^{1 / \lambda}-\log (N-1)(N-1)^{1 / \lambda}\right)$

Additionally,

$$
\begin{aligned}
& \text { PC1 } \Longleftrightarrow V_{0} \geq 10 q \pi+2 N \Longleftrightarrow \pi \leq \frac{V_{0}}{50}-\frac{10}{50} \equiv \Pi_{1}(\lambda) \\
& \text { PC2 } \Longleftrightarrow V_{0} \geq 14 q \pi+2 N^{1 / \lambda} \Longleftrightarrow \pi \leq \frac{V_{0}}{70}-\frac{2}{70} \cdot 5^{1 / \lambda} \equiv \Pi_{2}(\lambda) \\
& \text { PC3 } \Longleftrightarrow V_{0} \geq 10 q \pi+4(N-1)^{1 / \lambda} \Longleftrightarrow \pi \leq \frac{V_{0}}{50}-\frac{4}{50} 4^{1 / \lambda} \equiv \Pi_{3}(\lambda)
\end{aligned}
$$

Under $V_{0}=50$, all the participation constraints above induce $\pi \leq 1$. While PC1 is flat in the $(\lambda, \pi)$ space as $d \Pi_{1}(\lambda) / d \lambda=0$, the other two participation constraints are all upward sloping and strictly concave when $c(r)$ is concave. This enables us to plot the parameter ranges for equilibrium proposing orders in Figure 2 over the ranges of $\lambda \in[0.3,3]$ and $\pi \in[0,1]$. 


\section{Appendix II: Sequential Bargaining in a Tree Hierarchy}

Bargaining among a strict ordering of ranks, in a chain hierarchy, is investigated in the main sections. It is straightforward to generalize the analysis to a multi-tier chain with multiple agents of the same rank in each tier. Agents bargain within a tier before moving to the next tier. For other organizational forms, such as the hierarchy of trees, the process still take place as a sequence of one-to-one bargains due to its secretive nature. This is illustrated in the following example.

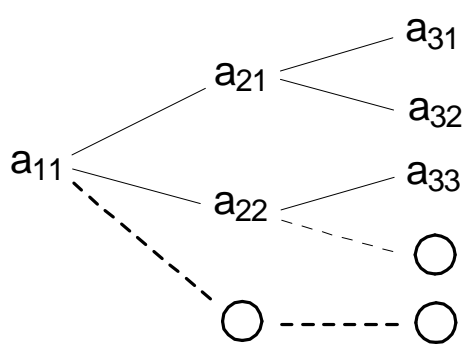

(i)

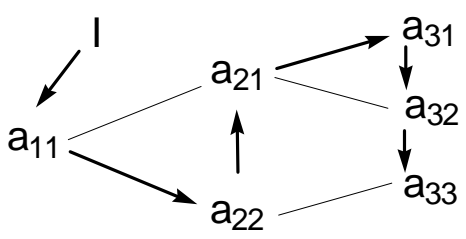

(ii)

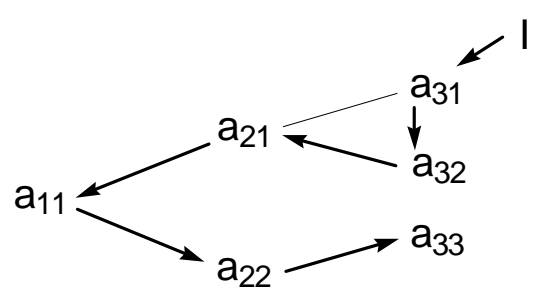

(iii)

Figure 3: An organization and the decision hierarchy.

An organization $\boldsymbol{S}$ headed by $a_{11}$ is a tree hierarchy structured as in Figure 3(i). Inside the organization, a decision is carried out by six agents: $a_{11}$ is of the highest rank; $a_{21}$ and $a_{22}$ are of the second rank and each manages a branch; $a_{31}, a_{32}$ and $a_{33}$ are of the lowest rank. These agents constitute the decision authority $\boldsymbol{A}$. Attempting to influence the decision of the authority, the initiator, for example, can propose to $a_{11}$ and then go down the tree by rank as in Figure 3(ii). Or she can propose to one of the lowest ranking agents and go up a branch, reaching the highest rank $a_{11}$, then go down the other branch as in Figure 3(iii). The equilibrium bargaining sequence selects agents one by one, depending on associated bargaining costs. Bargaining costs are determined by the positions of agents in the hierarchy, which may include, for example, the information costs of knowing others, and the access costs of approaching others across branches. Bargaining over a chain hierarchy demonstrates the key mechanism of the process of compromising a decision. General organization forms only complicate the calculation of costs while leaving the main results largely in effect. 